\title{
Comparison between Gel Pad Cooling Device and Water Blanket during Target Temperature Management in Cardiac Arrest Patients
}

\author{
Yoon Sun Jung', Kyung Su Kim', Gil Joon Suh",2, Jun-Hwi Cho ${ }^{3}$ \\ ${ }^{1}$ Department of Emergency Medicine, Seoul National University Hospital, Seoul; ${ }^{2}$ Department of Emergency Medicine, Seoul National University College of \\ Medicine, Seoul; ${ }^{3}$ Department of Emergency Medicine, Kangwon National University School of Medicine, Chuncheon, Korea
}

Background: Target temperature management (TTM) improves neurological outcomes for comatose survivors of out-of-hospital cardiac arrest. We compared the efficacy and safety of a gel pad cooling device (GP) and a water blanket (WB) during TM.

Methods: We performed a retrospective analysis in a single hospital, wherein we measured the time to target temperature $\left(<34^{\circ} \mathrm{C}\right)$ after initiation of cooling to evaluate the effectiveness of the cooling method. The temperature farthest from $33^{\circ} \mathrm{C}$ was selected every hour during maintenance. Generalized estimation equation analysis was used to compare the absolute temperature differences from $33^{\circ} \mathrm{C}$ during the maintenance period. If the selected temperature was not between $32^{\circ} \mathrm{C}$ and $34^{\circ} \mathrm{C}$, the hour was considered a deviation from the target. We compared the deviation rates during hypothermia maintenance to evaluate the safety of the different methods.

Results: A GP was used for 23 patients among of 53 patients, and a WB was used for the remaining. There was no difference in baseline temperature at the start of cooling between the two patient groups $\left(\mathrm{GP}, 35.7^{\circ} \mathrm{C}\right.$ vs. $\left.\mathrm{WB}, 35.6^{\circ} \mathrm{C} ; \mathrm{P}=0.741\right)$. The time to target temperature (134.2 minutes vs. 233.4 minutes, $P=0.056$ ) was shorter in the GP patient group. Deviation from maintenance temperature $(2.0 \%$ vs. $23.7 \%, \mathrm{P}<0.001)$ occurred significantly more frequently in the WB group. The mean absolute temperature difference from $33^{\circ} \mathrm{C}$ during the maintenance period was $0.19^{\circ} \mathrm{C}\left(95 \%\right.$ confidence interval $[\mathrm{Cl}], 0.17^{\circ} \mathrm{C}$ to $\left.0.21^{\circ} \mathrm{C}\right)$ in the GP group and $0.76^{\circ} \mathrm{C}\left(95 \% \mathrm{Cl}, 0.71^{\circ} \mathrm{C}\right.$ to $\left.0.80^{\circ} \mathrm{C}\right)$ in the WB group. GP significantly decreased this difference by $0.59^{\circ} \mathrm{C}\left(95 \% \mathrm{Cl}, 0.44^{\circ} \mathrm{C}\right.$ to $\left.0.75^{\circ} \mathrm{C} ; \mathrm{P}<0.001\right)$.

Conclusions: The GP was superior to the WB for strict temperature control during TTM.

Key Words: body temperature; heart arrest; hypothermia; induced hypothermia

\section{INTRODUCTION}

Out-of-hospital cardiac arrest has a low survival rate, ranging from 5\% to $35 \%$, and anoxic brain injury affects the morbidity and mortality of surviving patients [1,2]. A large randomized controlled study showed that target temperature management (TTM) improves the neurologic outcomes for comatose cardiac arrest survivors [3,4]. The American Heart Association's (AHA) recent guidelines recommend TTM as part of post-resuscitation care [5]. To

\section{Original Article}

Received: May 17, 2018

Revised: August 13, 2018

Accepted: August 22, 2018

Corresponding author Kyung Su Kim

Department of Emergency Medicine, Seoul National University College of Medicine, 103 Daehak-ro, Jongnogu, Seoul 03080, Korea Tel: +82-2-2072-4751 Fax: +82-2-3672-8871 E-mail:kanesu@gmail.com

Copyright (@) 2018 The Korean Society of Critical Care Medicine

This is an Open Access article distributed under the terms of Creative Attributions Non-Commercial License (http:// creativecommons.org/li-censes/by-nc/4.0/ which permits unrestricted noncommercial use, distribution, and reproduction in any medium, provided the original work is properly cited. 
achieve a safe and adequate therapeutic effect, clinicians should consider which technique is most appropriate [6-12]. Animal studies have shown that it is important to rapidly induce target temperature immediately after return of spontaneous circulation (ROSC) and general stability $[13,14]$.

TTM techniques can be invasive or noninvasive. Insertion of an endovascular catheter is an example of an invasive technique to induce hypothermia. An endovascular catheter can lower the body temperature faster than surface cooling methods, but its invasiveness can cause other side effects, and it is more inconvenient. Therefore, surface cooling methods are more commonly used [12,15]. Water blankets (WBs) and commercial gel pad cooling devices (GPs) are both surface applications, but they differ in several technical aspects. The WB is a plastic blanket containing circulating water; these are widely available in many hospitals in Korea. A GP, such as Arctic Sun (C. R. BARD Inc., Seoul, Korea), is a hydrogel-coated pad that circulates temperature-controlled water under negative pressure and adheres to the patient's abdomen, back, and thighs.

A previous study showed that a GP may be more effective for rapid induction and stable maintenance compared with a WB [16]. Currently in Korea, GPs are more frequently used than WBs for cooling [15]. However, WBs are still used in situations where a GP is not available or for economically disadvantaged patients. To date, no study has compared the safety and efficacy of GP and WB in South Korea. Consequently, there are no reliable data indicating which method is best for TTM. Herein, we compared GP and WB according to their ability to achieve rapid induction (efficacy) and stable maintenance (safety) in patients treated with TTM for post-resuscitation care.

\section{MATERIALS AND METHODS}

This was a retrospective observational study performed in one tertiary hospital's emergency intensive care unit (ICU), from January 2010 to May 2012. We collected and analyzed retrospective data from the electronic medical records of cardiac arrest survivors who were admitted to the ICU. We excluded pediatric patients (age $<18$ years), traumatic cardiac arrest patients, and patients who could not complete 24 hours of TTM (due to bleeding, transfer to another ICU, or death within 24 hours of ROSC). This study was approved by Seoul National University Hospital's Institutional Review Board (IRB No. 1212-088-450) and informed consent was waived.

Post-cardiac-arrest care was treated according to the 2010 AHA guidelines. During the study period, patients who sur-

\section{KEY MESSAGES}

- A gel pad cooling device provided faster induction and strict maintenance of therapeutic hypothermia than a water blanket.

- Patients treated with a water blanket experienced overcooling more frequently.

vived after cardiac arrest were admitted to the emergency ICU within 30 minutes after ROSC. Our post-cardiac arrest treatment protocol consisted of (1) adequate mechanical ventilation $\left(\mathrm{PaCO}_{2},<40 \pm 5 \mathrm{mmHg}\right)$ and oxygenation $\left(\mathrm{SaO}_{2}, 93 \%-98 \%\right)$, (2) early goal-directed hemodynamic optimization within 6 hours, (3) TTM, and (4) early percutaneous coronary intervention for high-risk patients. Comatose survivors of cardiac arrest who were indicated for TTM went through rapid cooling induction. When core body temperature reached $<34^{\circ} \mathrm{C}$, the temperature was maintained between $32^{\circ} \mathrm{C}$ and $34^{\circ} \mathrm{C}$ for 24 hours. After this maintenance period, the body temperature was increased, beginning at a speed of $0.25^{\circ} \mathrm{C} / \mathrm{hr}-0.5^{\circ} \mathrm{C} / \mathrm{hr}$.

Our institution's protocol for sedation during TTM involved an initial bolus injection of midazolam and vecuronium, followed by continuous infusion of both drugs. We treated patients with an Arctic Sun GP when it was available and when the patient's family approved its use; otherwise, we used a WB (Cincinnati Sub-Zero Blanketrol II) for TTM. The WB that we used had an auto-feedback regulation system to maintain the patient's body temperature at a set point.

Data included age, sex, arrest location (in or out of hospital), initial electrocardiography rhythm, initial body temperature at TTM onset, Acute Physiology and Chronic Health Evaluation (APACHE) II score at ICU admission, survival discharge rate, and neurologic outcome on day 28 . We used the cerebral performance category (CPC) as our neurological outcome measure. Ranks of CPC 1 and 2 were indicated as good neurologic outcomes. Body temperature was monitored using a rectal thermometer. After reaching target body temperature, the temperature farthest from $33^{\circ} \mathrm{C}$ was selected. Any selected temperature that fell outside the $32^{\circ} \mathrm{C}-34^{\circ} \mathrm{C}$ range was regarded as a deviation. Efficacy was evaluated based on the length of time between the start of induction and the time when target body temperature was achieved. Safety was evaluated based on the frequency of deviations and the degree of deviation from $33^{\circ} \mathrm{C}$ during the maintenance period.

\section{Statistics}

Categorical outcomes are expressed as frequencies and per- 
centages, and continuous variables are expressed as means and standard deviations or means and $95 \%$ confidence intervals. We used chi-square tests and Fisher exact test to compare categorical outcomes. For continuous variables, after confirming normality with the Shapiro-Wilks test, we used Student t-test for comparisons. We used the Wilcoxon ranksum test for non-normally distributed data. Times from the beginning of induction to target temperature below $34^{\circ} \mathrm{C}$ are shown as Kaplan-Meier curves, and we compared the two groups using the log-rank test. To analyze the degree of deviation from $33^{\circ} \mathrm{C}$ and show how individual patients' body temperatures changed, we used generalized estimating equations. We used STATA version 10.1 for all our statistical analyses, and a P-value $<0.05$ was considered statistically significant.

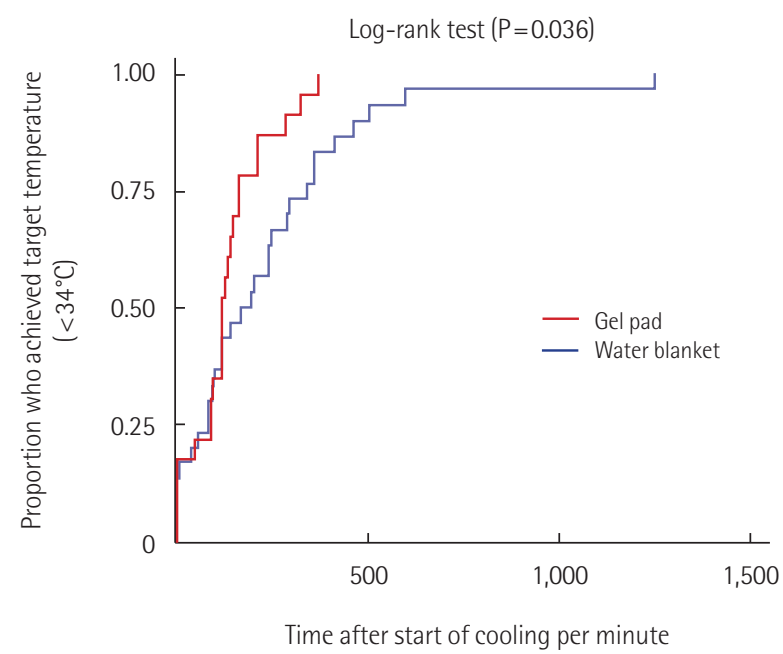

Figure 1. Patient ratio which reached target temperature every minute is expressed in a Kaplan-Meier curve. Comparisons between the two groups were made using the log-rank test.

\section{RESULTS}

We retrospectively analyzed data from 53 patients who achieved ROSC after cardiopulmonary resuscitation and who were treated with TTM. Thirty patients were treated with WB, and 23 patients were treated with GP. Demographic data and factors associated with resuscitation did not differ between the two groups. Patients were more frequently discharged alive in the GP group (GP, $73.9 \%$ vs. WB, 43.3\%; $\mathrm{P}=0.026$ ). The percentage of patients with good neurologic outcomes was not different between the two groups (GP, $26.1 \%$ vs. WB, $16.7 \%$; $\mathrm{P}=0.402$ ) (Table 1). There was no difference between two groups regard-

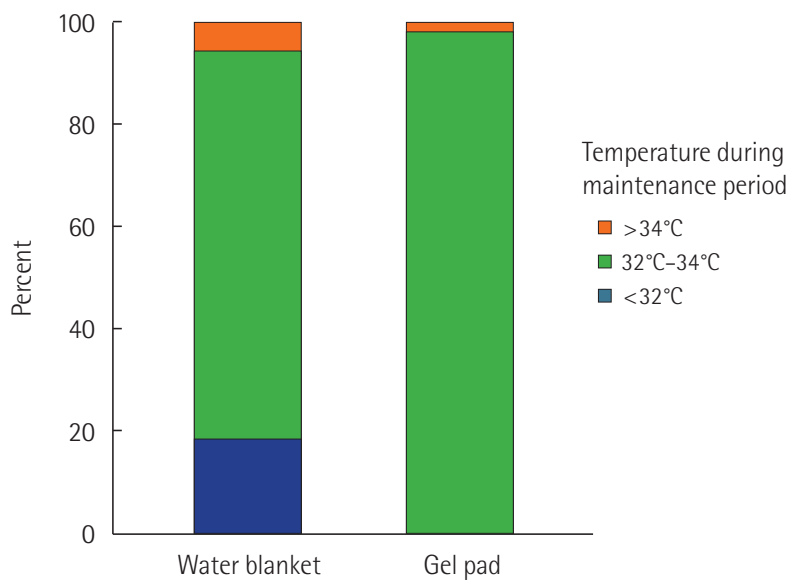

Figure 2. Bar graph representing distribution of temperature during maintenance period. The total length of maintenance phase was divided into three phases: hyperthermia $\left(>34^{\circ} \mathrm{C}\right)$, target temperature $\left(32^{\circ} \mathrm{C}-34^{\circ} \mathrm{C}\right)$, and hypothermia $\left(<32^{\circ} \mathrm{C}\right)$. Water blanket group experienced 119 hours (18.4\%) of hypothermia and 37 hours $(5.7 \%)$ of hyperthermia. Gel pad group experienced 10 hours $(1.9 \%)$ of hyperthermia.

Table 1. Age, sex, arrest site, initial rhythm, and outcomes

\begin{tabular}{lccc}
\hline Variable & Water blanket $(n=30)$ & Gel pad $(n=23)$ & P-value \\
\hline Age $(y r)$ & $69.4(64.8-73.9)$ & $62.5(55.7-69.4)$ & 0.081 \\
Male sex & $22(73.3)$ & $15(65.2)$ & 0.524 \\
OHCA & $25(83.3)$ & $21(91.3)$ & 0.396 \\
Cardiac cause & $15(50.0)$ & $8(34.8)$ & 0.268 \\
Shockable rhythm & $12(40.0)$ & $35.7(35.2-36.3)$ & 0.949 \\
Temperature at start of cooling $\left({ }^{\circ} \mathrm{C}\right)$ & $35.6(35.1-36.1)$ & $33.3(29.8-36.9)$ & 0.741 \\
APACHE II score at admission & $36.5(34.0-39.0)$ & $17(73.9)$ & 0.130 \\
Survival at discharge & $13(43.3)$ & $6(26.1)$ & 0.026 \\
Good neurology at day 28 & $5(16.7)$ & 0.402 & \\
\hline
\end{tabular}

Values are presented as mean (95\% confidence interval) or number (\%).

OHCA: out-of-hospital cardiac arrest; APACHE: Acute Physiology and Chronic Health Evaluation. 

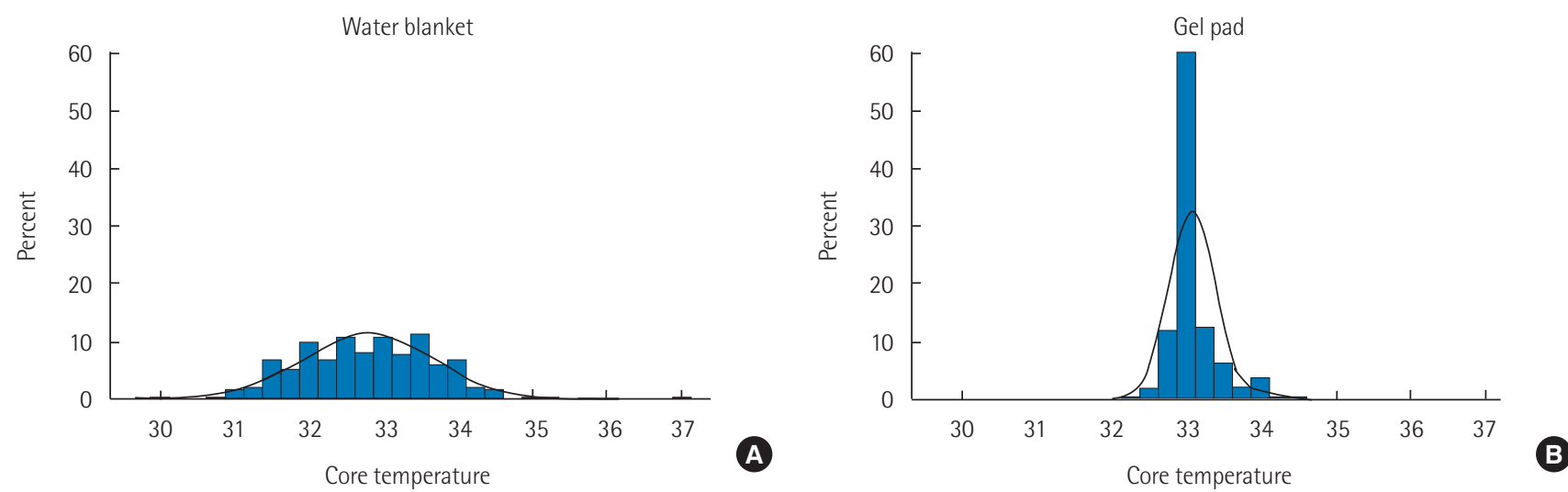

Figure 3. The distribution of core temperatures during maintenance of hypothermia by cooling device. (A) Water blanket group. (B) Gel pad group. The difference value from $33^{\circ} \mathrm{C}$ was analyzed with generalized estimating equation to compensate between the individual patient's changes of body temperature.

ing temperature at the start of cooling (GP, $35.7^{\circ} \mathrm{C}$ vs. $\mathrm{WB}, 35.6^{\circ} \mathrm{C}$; $\mathrm{P}=0.741$ ). Time to target temperature (GP, 134.2 minutes vs. $\mathrm{WB}, 233.4$ minutes; $\mathrm{P}=0.056$ ) was shorter in the GP group, but not significantly so. The proportion of patients who reached the target temperature $\left(\leq 34^{\circ} \mathrm{C}\right)$ within 4 hours from the start of cooling was not different (GP, $87.0 \%$ vs. WB, $63.3 \%$; $\mathrm{P}=0.053$ ) between the two groups. The proportion of patients who reached the target temperature every minute is expressed as a Kaplan-Meier curve, which showed that the GP group reached the target temperature more rapidly than the WB group (Figure 1). The total maintenance duration (GP, 22.7 hours vs. WB, 21.6 hours; $\mathrm{P}=0.091$ ) was not different between the two groups. However, deviations from maintenance (GP, $2.0 \%$ vs. WB, $23.7 \%$; $\mathrm{P}<0.001)$ were more frequently observed in the WB group. Most deviations in the WB group (119/156, 76.3\%) were hypothermic events $\left(<32^{\circ} \mathrm{C}\right)$ (Figure 2). However, all deviations in the GP group were hyperthermic events $\left(>34^{\circ} \mathrm{C}\right)$. The mean absolute temperature difference from $33^{\circ} \mathrm{C}$ during the maintenance period was $0.19^{\circ} \mathrm{C}\left(95 \% \mathrm{CI}, 0.17^{\circ} \mathrm{C}\right.$ to $\left.0.21^{\circ} \mathrm{C}\right)$ in the GP group and $0.76^{\circ} \mathrm{C}\left(95 \% \mathrm{CI}, 0.71^{\circ} \mathrm{C}\right.$ to $\left.0.80^{\circ} \mathrm{C}\right)$ in the $\mathrm{WB}$ group. Generalized estimating equations revealed that the GP reduced the difference value from $33^{\circ} \mathrm{C}$ to $0.59^{\circ} \mathrm{C}\left(95 \% \mathrm{CI}, 0.44^{\circ} \mathrm{C}\right.$ to $0.75^{\circ} \mathrm{C} ; \mathrm{P}<0.001$ ) compared with the WB (Figure 3 ).

\section{DISCUSSION}

Although the number of patients who reached the target temperature within 4 hours of the start of cooling was not statistically different between the two groups (GP, $87.0 \%$ vs. WB, $63.3 \%$; $\mathrm{P}=0.053)$, the proportion who achieved the target temperature, according to Kaplan-Meier analysis, was significantly different $(\mathrm{P}=0.036)$. This result is consistent with a previous randomized clinical trial that compared GP and WB [16].

The deviation period during maintenance was significantly longer in WB patients compared with GP patients. Furthermore, generalized estimating equations showed that GP significantly reduced the absolute difference from target temperature $\left(33^{\circ} \mathrm{C}\right)$ by $0.59^{\circ} \mathrm{C}$ compared with WB. Consequently, GP prevented the body temperature from going beyond the therapeutic range, especially overcooling. Recent guidelines recommend selecting and maintaining a constant temperature between $32^{\circ} \mathrm{C}$ and $36^{\circ} \mathrm{C}[5]$.

There was no difference in neurological prognosis on day 28 between the WB and GP groups, but the survival discharge rate was higher in the GP group than that in the WB group. This retrospective observational study aimed to compare the speed of cooling and the stability the target temperature between the two surface cooling methods. There may have been a selection bias that influenced the differences we saw in survival discharge rates. Therefore, this small sample study cannot offer reliable guidelines for clinical use of specific cooling methods. A previous randomized controlled trial found no difference in survival discharge rates [16], and there are no other randomized clinical trials that show an enhanced benefit of GP. However, we think both tools are appropriate for use in TTM. Clinicians should choose which tool is best based on individual patient factors, resource availability, and cost.

A recent study by Coppler et al. [15] reported that GP was used in 14 (58\%) of 24 hospitals in Korea, while WB was used in $17 \%$. The national utilization rate was higher than that in our single-center study because our study analyzed data from 2010 to 2012. During the study period, the TTM protocol remained unchanged. GP was not available in our hospital until March 2011; prior to that, only WB was used for TTM. After 
March 2011, both GP and WB were available for TTM.

As mentioned above, this study has several limitations. First, this is a retrospective observational study that compared cooling speed and target-temperature stability. Thus, we cannot make strong conclusions about the clinical benefits of GP with respect to survival discharge rate or neurologic outcomes. Second, we did not discuss the potential benefits of strict temperature management. The WB group experienced overcooling more frequently. However, that did not result in significant complications, such as significant bradycardia, pneumonia, and hyperglycemia (Supplementary Table 1). In conclusion, a GP cooling device was superior to a WB for strict temperature control during TTM.

\section{CONFLICT OF INTEREST}

No potential conflict of interest relevant to this article was reported.

\section{ORCID}

Yoon Sun Jung https://orcid.org/0000-0001-7408-4436

Kyung Su Kim https://orcid.org/0000-0002-3897-0278

Gil Joon Suh https://orcid.org/0000-0001-5163-2217

Jun-Hwi Cho https://orcid.org/0000-0001-8558-3564

\section{SUPPLEMENTARY MATERIAL}

The online-only Supplement data are available with this article online: https://doi.org/acc.2018.00192.

\section{REFERENCES}

1. Lim C, Alexander MP, LaFleche G, Schnyer DM, Verfaellie M. The neurological and cognitive sequelae of cardiac arrest. Neurology 2004;63:1774-8.

2. Wachelder EM, Moulaert VR, van Heugten C, Verbunt JA, Bekkers SC, Wade DT. Life after survival: long-term daily functioning and quality of life after an out-of-hospital cardiac arrest. Resuscitation 2009;80:517-22.

3. Bernard SA, Gray TW, Buist MD, Jones BM, Silvester W, Gutteridge $\mathrm{G}$, et al. Treatment of comatose survivors of out-ofhospital cardiac arrest with induced hypothermia. N Engl J Med 2002;346:557-63.

4. Hypothermia after Cardiac Arrest Study Group. Mild therapeutic hypothermia to improve the neurologic outcome after cardiac arrest. N Engl J Med 2002;346:549-56.
5. Callaway CW, Donnino MW, Fink EL, Geocadin RG, Golan E, Kern KB, et al. Part 8: post-cardiac arrest care: 2015 American Heart Association guidelines update for cardiopulmonary resuscitation and emergency cardiovascular care. Circulation 2015;132(18 Suppl 2):S465-82.

6. Holzer M, Müllner M, Sterz F, Robak O, Kliegel A, Losert H, et al. Efficacy and safety of endovascular cooling after cardiac arrest: cohort study and Bayesian approach. Stroke 2006;37: 1792-7.

7. Flint AC, Hemphill JC, Bonovich DC. Therapeutic hypothermia after cardiac arrest: performance characteristics and safety of surface cooling with or without endovascular cooling. Neurocrit Care 2007;7:109-18.

8. Polderman KH. Application of therapeutic hypothermia in the intensive care unit: opportunities and pitfalls of a promising treatment modality. Part 2: practical aspects and side effects. Intensive Care Med 2004;30:757-69.

9. Merchant RM, Abella BS, Peberdy MA, Soar J, Ong ME, Schmidt GA, et al. Therapeutic hypothermia after cardiac arrest: unintentional overcooling is common using ice packs and conventional cooling blankets. Crit Care Med 2006;34(12 Suppl): S490-4.

10. Hoedemaekers CW, Ezzahti M, Gerritsen A, van der Hoeven JG. Comparison of cooling methods to induce and maintain normo- and hypothermia in intensive care unit patients: a prospective intervention study. Crit Care 2007;11:R91.

11. Gillies MA, Pratt R, Whiteley C, Borg J, Beale RJ, Tibby SM. Therapeutic hypothermia after cardiac arrest: A retrospective comparison of surface and endovascular cooling techniques. Resuscitation 2010;81:1117-22.

12. Haugk M, Sterz F, Grassberger M, Uray T, Kliegel A, Janata A, et al. Feasibility and efficacy of a new non-invasive surface cooling device in post-resuscitation intensive care medicine. Resuscitation 2007;75:76-81.

13. Carroll M, Beek O. Protection against hippocampal CA1 cell loss by post-ischemic hypothermia is dependent on delay of initiation and duration. Metab Brain Dis 1992;7:45-50.

14. Kuboyama K, Safar P, Radovsky A, Tisherman SA, Stezoski SW, Alexander H. Delay in cooling negates the beneficial effect of mild resuscitative cerebral hypothermia after cardiac arrest in dogs: a prospective, randomized study. Crit Care Med 1993;21:1348-58.

15. Coppler PJ, Sawyer KN, Youn CS, Choi SP, Park KN, Kim YM, et al. Variability of Post-Cardiac Arrest Care Practices Among Cardiac Arrest Centers: United States and South Korean Dual Network Survey of Emergency Physician Research Principal Investigators. Ther Hypothermia Temp Manag 2017;7:30-5. 
16. Heard KJ, Peberdy MA, Sayre MR, Sanders A, Geocadin RG, Dixon SR, et al. A randomized controlled trial comparing the
Arctic Sun to standard cooling for induction of hypothermia after cardiac arrest. Resuscitation 2010;81:9-14. 
Jung YS, et al. Comparing External Cooling Devices

Supplementary Table 1. Complications during target temperature management

\begin{tabular}{lccc}
\hline Variable & $\begin{array}{c}\text { Water blanket } \\
(n=30)\end{array}$ & $\begin{array}{c}\text { Gel pad } \\
(n=23)\end{array}$ & P-value \\
\hline Antibiotics & $29(96.7)$ & $19(82.6)$ & 0.154 \\
Pneumonia & $7(23.3)$ & $4(17.4)$ & 0.738 \\
Bradycardia (<60/min) & $12(40.0)$ & $8(34.8)$ & 0.779 \\
Tachycardia (>150/min) & 0 & $1(4.4)$ & 0.434 \\
Vasopressor & $22(73.3)$ & $14(60.9)$ & 0.384 \\
Hyperglycemia $(>144)$ & $5(16.7)$ & $6(26.1)$ & 0.402 \\
\hline
\end{tabular}

Values are presented as number (\%). Fisher exact test was used. 